\title{
(2) OPEN ACCESS \\ Maximising the impact of global and national physical activity guidelines: the critical role of communication strategies
}

\author{
Karen Milton (1) ,' Adrian E Bauman, ${ }^{2}$ Guy Faulkner, ${ }^{3}$ Gerard Hastings, ${ }^{4}$ \\ William Bellew, ${ }^{2}$ Chloë Williamson (D) , ${ }^{5}$ Paul Kelly (D) ${ }^{5}$
}

'Norwich Medical School, University of East Anglia, Norwich, UK

${ }^{2}$ Sydney School of Public Health, University of Sydney, Sydney, New South Wales, Australia ${ }^{3}$ University of British Columbia, Vancouver, British Columbia, Canada

${ }^{4}$ Institute for Social Marketing, University of Stirling, Stirling, UK ${ }^{5}$ Physical Activity for Health Research Centre, The University of Edinburgh, Edinburgh, UK

\section{Correspondence to} Dr Karen Milton, Norwich Medical School, University of East Anglia Faculty of Medicine and Health Sciences, Norwich NR4 7TJ, UK

k.milton@uea.ac.uk

Accepted 17 August 2020
Check for updates

(c) Author(s) (or their employer(s)) 2020. Re-use permitted under CC BY-NC. No commercial re-use. See rights and permissions. Published by BMJ.

To cite: Milton $\mathrm{K}$, Bauman AE, Faulkner $\mathrm{G}$, et al. Br I Sports Med 2020:54:1463-1467.

\begin{abstract}
Objectives Physical activity guidelines are evidencebased statements on recommended physical activity levels for good health. Guidelines, in isolation, are unlikely to increase population levels of physical activity; appropriate and effective communication is fundamental to maximising their impact. The aim of this paper is to provide a planning framework for physical activity guideline communication, including an overview of key audiences, aims and approaches.

Methods All authors considered and agreed on the three broad issues to address by consensus. We identified key sources of evidence through scoping of the literature and our knowledge of the research area.

Results Whether guidelines are global or national, communication of the physical activity guidelines should be informed by: (1) a situational analysis that considers the context in which the communication will take place and (2) a stakeholder analysis to determine the key target audiences for the communication and their values, needs and preferences. Audiences include policy-makers within and outside the health sector, other key stakeholders, the general public, specific population subgroups, health professionals and non-health professionals with a role in physical activity promotion. The aims and approach to communication will differ depending on the target audience.

Conclusion Communication to raise awareness and knowledge of the physical activity guidelines must be supported by policies, environments and opportunities for physical activity. Besides the intrinsic value of the physical activity guidelines, it is essential that substantial effort is put in to diligently planning, funding and implementing their communication from the outset.
\end{abstract}

\section{INTRODUCTION}

Physical activity guidelines, such as those developed by the World Health Organization (WHO) or national health agencies, are evidence-based statements on recommended physical activity levels for good health. They provide recommendations on the amount of time and types of physical activity that different population groups should do to benefit health, as well as recommendations for minimising sedentary time. These guidelines are typically developed by expert groups, based on the best available scientific evidence.

In 2010, the WHO identified a list of functions served by physical activity guidelines including:

- Providing consensus on the scientific evidence.
- Raising awareness and knowledge of the health benefits of physical activity among different groups.

- Informing national policy to support implementation actions.

- Underpinning monitoring and surveillance.

- Guiding future research directions. ${ }^{1}$

The traditional 'rational choice' model of health assumes that increases in awareness and knowledge about the risks or benefits of health behaviours directly influence the lifestyle choices that people make. $^{2}$ It is now widely recognised that this is not the case, and that the existence of guidelines, in isolation, is highly unlikely to lead to changes in health behaviours at the population level. ${ }^{3} \mathrm{~A}$ coherent communications strategy, ensuring that the right groups of people receive the most useful information in an appropriate way, is necessary for broad policy, practice and physical activity behaviour impact. This includes dissemination of the guidelines (ie, the strategic distribution of information) using appropriate communication channels and messages, and supporting implementation actions (ie, changes in policy and practice to provide appropriate environments and opportunities for physical activity).

Clear communication strategies to accompany the publication of physical activity guidelines has not been usual practice. It is hardly surprising that, as a result, awareness of physical activity guidelines in many countries has remained low. ${ }^{4-8}$ The aim of this paper is to provide a planning framework for communication of physical activity guidelines. The specific objectives are to: (1) outline a process for communication planning and implementation; (2) describe the key audiences, aims and approaches to physical activity guideline communication and (3) identify future research directions.

\section{METHODS}

Through informal discussions, all authors debated and agreed on the key issues to address in this paper. Through our knowledge of the research area and scoping of the relevant literature, including our collective reference libraries, we identified key sources of evidence which we synthesised. This is presented in three parts, reflecting our three objectives.

\section{PART 1: A PLANNING FRAMEWORK FOR PHYSICAL ACTIVITY COMMUNICATIONS}

In developing an integrated communications approach for physical activity, methods from social 


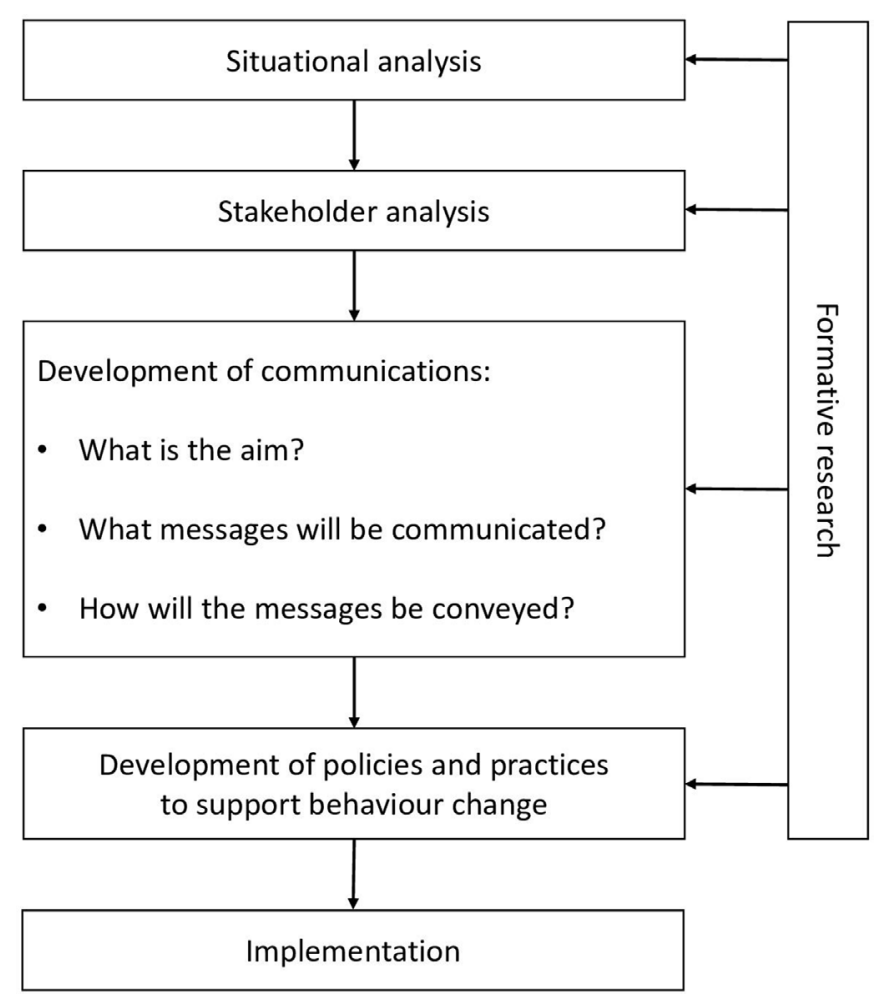

Figure 1 A planning framework for physical activity communication, adapted from Hastings. ${ }^{9}$

marketing provide a useful guide. Figure 1 outlines a planning framework for physical activity communication, adapted from social marketing theory. ${ }^{9}$ The framework emphasises that effective communication needs to be informed by extensive formative research. The WHO has previously highlighted the importance of undertaking formative, and specifically qualitative research, to ensure guidelines are not only based on scientific evidence but are also relevant and applicable to end-users, therefore, maximising potential use and effectiveness. ${ }^{10}$ This extends to the actions stakeholders take to maximise impact of the guidelines, including their communication and the implementation of policies and practices to support behavioural change.

As shown in figure 1, a situational analysis that considers the context in which the communication will take place should precede development of a communication strategy. Such an analysis could include factors such as culture, ethnic diversity, existing social norms and the current provision for physical activity promotion. ${ }^{1}$ The next stage is a stakeholder analysis, which involves deciding the key audiences for the communication and establishing their values, needs and preferences. This should be informed by previous research and, where gaps in the evidence remain, primary formative research. Some key objectives of formative research with different stakeholder groups are summarised in table 1 . The situational and stakeholder analyses inform both the messages and communication channels (the large box in the centre of figure 1). This is central to physical activity guideline communication, and thus, we have expanded on this in part 2 of the paper where we explain the key audiences, aims and approaches to communication.

The social marketing model (figure 1) highlights the need for communications to be supported by policies and practices to support behavioural change, including the creation of appropriate environments and opportunities for physical activity. Investment of time and resources in formative research is critical to the success of communication and other supportive policies and practices to support behavioural change. Process evaluation of implementation (eg, expenditure, reach) and outcome evaluation of effectiveness (eg, impact on awareness, knowledge and behaviour) are critical for building the evidence-base on 'what works' in physical activity communication, to inform future communication efforts.

\section{PART 2: KEY AUDIENCES, AIMS AND APPROACHES}

There are two broad purposes for communication-advocacy and education-and the approach used depends on the target audience and the aim(s) of the communication. Advocacy is a form of communication aimed at strategically influencing people and mobilising them to create change. ${ }^{11}$ The WHO defines advocacy as 'a combination of individual and social actions designed to gain political commitment, policy support, social acceptance and systems support for a particular health goal or programme'. ${ }^{12}$ Advocacy seeks to raise the profile of an issue, gain support at multiple levels and increase the priority placed on taking appropriate action. ${ }^{13}$ From a physical activity perspective, advocacy should pursue national adoption of physical activity guidelines as well as changes in legislation, policies, environments and opportunities to support active lifestyles. For advocacy communications, the target audience is usually policy-makers and/or other key stakeholders. Educational approaches are more commonly targeted at the general public, specific population subgroups and professionals within and outside of the health sector with a potential role in physical activity promotion. This type of communicating involves 'translating' the guidelines into 'publicfacing' messages, to educate and hopefully motivate changes in behaviour or practice. ${ }^{14}$

Table 1 highlights a range of diverse target audiences for physical activity communication, along with the aims of communicating with these audiences. Below we describe in more detail some considerations when communication is targeted at: policymakers and other key stakeholders (columns 1-3); the general public and specific population subgroups (columns 4 and 5); and health and non-health professionals with a potential role in physical activity promotion (columns 6 and 7). While there are a range of target audiences for communication, it is important that communication activities and the development and implementation of policies and practices to support behavioural change are coordinated, such that the 'supply' in terms of environments and opportunities is equipped to cope with any potential change in demand resulting from the communication activities.

Communicating to policy-makers and other key stakeholders Advocacy is a crucial tool when attempting to generate interest in and support for the physical activity agenda. Key target audiences for advocacy include policy-makers (who may or may not be elected officials) within and outside the health sector (including transport, planning, education, workplaces, sport, parks and recreation) (columns 1 and 2 in table 1). In addition, target audiences include: Faculties of Public Health or Sport and Exercise Medicine Associations, to encourage these stakeholders to support the physical activity agenda; heads of academic institutions, to encourage the integration of physical activity into relevant curricula; chief executive officers and workplace managers, to establish and support workplace physical activity policies; journalists and the media, to raise the volume of reporting on the topic; funding agencies, to secure greater investment in physical activity research; charities and other organisations, to encourage greater provision of physical activity opportunities for the 
Table 1 Communication aims and key audiences

\begin{tabular}{|c|c|c|c|c|c|c|c|}
\hline \multirow[b]{2}{*}{$\begin{array}{l}\text { Target of } \\
\text { communications }\end{array}$} & 1 & 2 & 3 & 4 & 5 & 6 & 7 \\
\hline & $\begin{array}{l}\text { Policy-makers within } \\
\text { the health sector }\end{array}$ & $\begin{array}{l}\text { Policy-makers } \\
\text { outside the health } \\
\text { sector }\end{array}$ & Key stakeholders & General public & $\begin{array}{l}\text { Specific population } \\
\text { subgroups }\end{array}$ & Health professionals & $\begin{array}{l}\text { Non-health } \\
\text { professionals }\end{array}$ \\
\hline $\begin{array}{l}\text { Purpose of } \\
\text { communication }\end{array}$ & Advocacy & Advocacy & Advocacy & Education & Education & Education & Education \\
\hline $\begin{array}{l}\text { Aim of guideline } \\
\text { communication }\end{array}$ & $\begin{array}{l}\text { Encourage national } \\
\text { adoption of the WHO } \\
\text { physical activity } \\
\text { guidelines and/or } \\
\text { national guidelines } \\
\text { Encourage integration } \\
\text { of physical activity } \\
\text { into all relevant health } \\
\text { policies } \\
\text { Encourage scaled- } \\
\text { up and coordinated } \\
\text { actions. }\end{array}$ & $\begin{array}{l}\text { Increase recognition } \\
\text { of the role of physical } \\
\text { activity in contributing } \\
\text { to a broad range of } \\
\text { diverse yet related } \\
\text { agendas } \\
\text { Increase cross-sectoral } \\
\text { engagement in } \\
\text { policies and actions } \\
\text { in sectors outside of } \\
\text { health that promote } \\
\text { physical activity (ie, } \\
\text { use a 'health in all } \\
\text { policies' perspective). }\end{array}$ & $\begin{array}{l}\text { Increase awareness } \\
\text { of the role that a } \\
\text { range of stakeholders } \\
\text { can play in gaining } \\
\text { wider recognition and } \\
\text { greater support for } \\
\text { the physical activity } \\
\text { agenda } \\
\text { Engage a wide group } \\
\text { of stakeholders } \\
\text { in advocating for } \\
\text { physical activity } \\
\text { guidelines and the } \\
\text { implementation of } \\
\text { supportive policies } \\
\text { and practices. }\end{array}$ & $\begin{array}{l}\text { Increase awareness } \\
\text { and knowledge of } \\
\text { the physical activity } \\
\text { guidelines } \\
\text { Increase awareness } \\
\text { and knowledge of } \\
\text { how to achieve the } \\
\text { physical activity } \\
\text { guidelines } \\
\text { Reduce (real and } \\
\text { perceived) barriers to } \\
\text { being physically active } \\
\text { Influence attitudes, } \\
\text { intentions, confidence } \\
\text { and motivation to be } \\
\text { physically active. }\end{array}$ & $\begin{array}{l}\text { Increase awareness } \\
\text { and knowledge of } \\
\text { the physical activity } \\
\text { guidelines } \\
\text { Increase awareness } \\
\text { and knowledge of } \\
\text { how to achieve the } \\
\text { physical activity } \\
\text { guidelines, tailored } \\
\text { to each subgroup's } \\
\text { circumstances } \\
\text { (eg, persons with } \\
\text { disabilities) or cultural } \\
\text { influences } \\
\text { (eg, different ethnic } \\
\text { groups) } \\
\text { Reduce (real and } \\
\text { perceived) barriers to } \\
\text { being physically active } \\
\text { Influence attitudes, } \\
\text { intentions, confidence } \\
\text { and motivation to be } \\
\text { physically active. }\end{array}$ & $\begin{array}{l}\text { Increase awareness } \\
\text { and knowledge of } \\
\text { the physical activity } \\
\text { guidelines } \\
\text { Increase knowledge, } \\
\text { skills and confidence } \\
\text { in promoting physical } \\
\text { activity } \\
\text { Encourage integration } \\
\text { of physical activity } \\
\text { promotion into } \\
\text { routine practice. }\end{array}$ & $\begin{array}{l}\text { Increase awareness } \\
\text { and knowledge of } \\
\text { the physical activity } \\
\text { guidelines } \\
\text { Increase knowledge, } \\
\text { skills and confidence } \\
\text { in promoting } \\
\text { physical activity, } \\
\text { solely and as part } \\
\text { of multidisciplinary } \\
\text { or multisector } \\
\text { collaborations } \\
\text { Encourage integration } \\
\text { of physical activity } \\
\text { promotion into } \\
\text { routine practice. }\end{array}$ \\
\hline $\begin{array}{l}\text { Formative research } \\
\text { aims }\end{array}$ & $\begin{array}{l}\text { Increase understanding } \\
\text { of how physical activity } \\
\text { promotion can be } \\
\text { embedded into current } \\
\text { and future health policy } \\
\text { and practice. }\end{array}$ & $\begin{array}{l}\text { Gain insights into } \\
\text { policy-makers' } \\
\text { priorities to inform } \\
\text { greater alignment } \\
\text { with the physical } \\
\text { activity agenda. }\end{array}$ & $\begin{array}{l}\text { Understand } \\
\text { stakeholders and their } \\
\text { networks and gain } \\
\text { insight into the tools } \\
\text { and resources needed } \\
\text { to support advocacy } \\
\text { efforts. }\end{array}$ & $\begin{array}{l}\text { Understand the } \\
\text { values, needs and } \\
\text { preferences of the } \\
\text { general public to } \\
\text { inform messages } \\
\text { and communication } \\
\text { channels. }\end{array}$ & $\begin{array}{l}\text { Understand the } \\
\text { values, needs and } \\
\text { preferences of specific } \\
\text { population subgroups } \\
\text { to inform tailored and } \\
\text { targeted messages } \\
\text { and communication } \\
\text { channels. }\end{array}$ & $\begin{array}{l}\text { Gain insights into } \\
\text { what training, tools } \\
\text { and resources might } \\
\text { support health } \\
\text { professionals in } \\
\text { communicating } \\
\text { the guidelines and } \\
\text { promoting physical } \\
\text { activity behaviours to } \\
\text { patients, clients or the } \\
\text { public. }\end{array}$ & $\begin{array}{l}\text { Gain insights into } \\
\text { what training, tools } \\
\text { and resources might } \\
\text { support non-health } \\
\text { professionals in } \\
\text { the development } \\
\text { of supportive } \\
\text { environments and } \\
\text { opportunities for } \\
\text { physical activity. }\end{array}$ \\
\hline
\end{tabular}

populations they serve; and grass-roots community groups and civil society, to encourage greater action at a local level (column 3 in table 1).

Effective physical activity advocacy requires a communication style that is clear, concise, simple and direct, and most importantly, convincing of the need to act. ${ }^{11}$ It requires selective distillation of the evidence, which can be presented in very short memo or briefing style summaries. In addition to highlighting the magnitude and importance of physical inactivity, these communications should also highlight solutions to addressing low activity levels. Convincing policy-makers and other stakeholders that there are appropriate solutions to low activity levels, which are supported by good evidence of effectiveness and ideally cost-effectiveness, will increase the likelihood of gaining support. ${ }^{15}$ Physical activity advocacy can be undertaken by a range of different individuals (authoritative figures, experts or 'champions') and/or groups (eg, walking or bicycle groups). ${ }^{16}$ Advocacy is typically led by people from outside of government including academics, non-government organisations, professionals (such as doctors or teachers), business and community leaders and also committed members of the public. ${ }^{11}$

The physical activity agenda has many potential allies outside of health if priorities can be aligned. ${ }^{17}$ There is a lack of information available on how best to communicate with different stakeholder groups outside of health, however, experience suggests that it is important to 'speak their language' and emphasise the benefits of physical activity that are likely to resonate with their current priorities. ${ }^{18}$ It is important to communicate that time devoted to physical activity is not a distraction from the key goals of each sector or organisation, but an important contributor to their desired outcomes. For example, for the education sector, communication regarding the contribution of physical activity to educational attainment or reducing injuries by providing safe routes for students to actively commute to and from school, may help in demonstrating alignment of the two-physical activity and education-agendas. When communicating with the transport sector, a focus on how active travel (walking and cycling) can contribute to reducing traffic congestion and/or carbon emissions might be appropriate.

Changing societal and political views can be challenging, and therefore, advocacy efforts may need to be sustained over a long period of time. ${ }^{19}$ However, as more individuals and groups realise the importance of physical activity, this will create a 'ground-swell' or societal norm that will eventually become difficult to ignore. This progressive growth in support and action has been demonstrated in other areas of public health including tobacco control ${ }^{2021}$ and, more recently, climate change. ${ }^{22}$

\section{Communicating to the general public and specific population subgroups}

Williamson et al presented a conceptual framework for understanding, developing and evaluating physical activity messages for public communication (columns 4 and 5 in table 1 ). The framework outlines several important considerations including: 
- The need to identify who (which population groups) the intended audience are.

- Understanding what outcome(s) the message is targeted at (eg, awareness, knowledge, motivation, confidence).

- Deciding the type of information to use (eg, Why? How much? How to?).

- Considering the message framing (eg, focused on the positives of being active or the risks of being inactive).

- Selecting the communication channels for delivery (eg, television, radio, poster, online).

- The setting in which it is delivered (eg, home, schools, primary care, community).

- The frequency of communication and the duration over which it will be delivered.

- And agreeing on the provider or source of communication (eg, government, trusted professional, accredited body, celebrity). ${ }^{23}$

It is important to determine the aim of communications, as this will influence subsequent decisions about the type of messages to use. ${ }^{23}$ It is also important to distinguish the actual guidelines from the messaging that may be developed to communicate the intent or spirit of those guidelines. If the aim is to increase awareness and knowledge of the physical activity guidelines, communicating thresholds of activity (eg, $150 \mathrm{~min}$ per week) may be necessary. If the aim, however, is to increase motivation or confidence for behaviour change, the communication may not mention physical activity guidelines. The messaging may be generic (eg, move more) rather than specifying guideline thresholds. In addition, conveying positive images of physical activity or information on how, when and where to be physically active may be more appropriate than communicating the guidelines themselves. ${ }^{24}$ There is still a need for stronger and independent evaluations of different approaches to understand what sorts of messages (text and images) work best. Tailored and gainframed messages that focus on short-term outcomes, including social and mental health as well as physical health, appear to hold promise as a basis for future investigation. ${ }^{14} 25$ It is also important to consider the emotional and persuasive dimensions of the communication, as humans respond to both conative and cognitive elements of messages. ${ }^{26}$

Implementation of community-wide public education and awareness campaigns for physical activity is underpinned by evidence that appropriate, relevant and well-resourced campaigns are effective at influencing awareness and knowledge and for increasing levels of motivation, which are known antecedents of physical activity behaviours. ${ }^{27}{ }^{28}$ It is recognised, however, that mass media alone is unlikely to directly change behaviour and campaigns in isolation are not recommended. ${ }^{29}$ Campaigns are most likely to be effective if they adopt a social marketing approach, combining communications with supportive policies, environments and opportunities for physical activity. ${ }^{30} 31$ These activities are described as 'policies and practices to support behaviour change' in figure 1 .

\section{Communicating to professionals with a role in physical activity promotion}

A range of professionals have a potential role in encouraging physical activity participation among different groups. First, health professionals have the potential to provide individually tailored advice and recommendations through consultations and counselling and providing health education materials in routine care (column 6 in table 1). Second, there are a range of organisations and professionals with access to groups of people to whom they could promote physical activity including teachers, sports and fitness organisations, sports clubs and coaches, occupational health staff within workplaces, clergy in faith based settings, charities and walking, cycling and play associations. ${ }^{32}$ Third, there are professionals with the potential to influence environments for physical activity including transport engineers and town planners (the latter two groups are depicted in column 7 in table 1).

Healthcare is recognised as an important setting for physical activity promotion. However, research suggests that over $70 \%$ of doctors do not discuss the benefits of physical activity with their patients, ${ }^{33}$ citing a lack of training, knowledge, confidence and time as barriers. ${ }^{3435}$ In recent years, there have been attempts to increase awareness and knowledge of the physical activity guidelines among health professionals, for example, through the development of infographics (charts or diagrams aimed at presenting the guidelines in a visual format). ${ }^{36}$ Attempts have been made to increase knowledge, confidence and skills through embedding physical activity promotion into the curricula of undergraduate medical and other health related courses, as well as through continued professional development opportunities. ${ }^{37-39}$ There have also been attempts to integrate standardised pathways for the promotion of physical activity (through assessment and counselling) into standard practice. ${ }^{40} 41$ While these developments are encouraging, limited robust evaluation of such initiatives has been undertaken. Therefore, the most appropriate approaches to increasing knowledge among health professionals, the best tools for supporting them to undertake physical activity assessment and counselling, and the most influential ways to change practice remain unknown.

As mentioned, there are a wide range of professionals outside of the health sector with a potential role in promoting physical activity. It is essential to better understand each sector's needs and develop acceptable and effective communication methods and tools to support these groups of professionals in promoting physical activity as part of their strategic priorities and routine work.

\section{PART 3: FUTURE RESEARCH DIRECTIONS}

A number of research gaps are evident. There is a substantial evidence gap in how to foster the adoption of physical activity guidelines and how to advocate for engagement and action. There is a clear research opportunity to capture learning and recommendations from key stakeholders who have been involved in the physical activity agenda globally and nationally, as well as to learn from what has been successful in other areas of public health.

While we have data on awareness and knowledge of physical activity guidelines from several high-income countries, further research is needed into levels of awareness and knowledge of physical activity guidelines in low-income and middle-income countries. In terms of communicating physical activity guidelines to the public, there is a need to better understand the impact of presenting the guidelines in different ways (eg, 'some is good, more is better' vs ' $150 \mathrm{~min}$ '). There is a need for robust and independent evaluation of different communication approaches to understand what sorts of messages (text and images) work best with diverse audience groups. It is important to understand preferences for different types of messages, as well as the types of messages most likely to motivate behavioural change, and from whom those messages might be optimally received (eg, childcare workers, physicians, celebrities or 'people who look like me'). This includes emotional approaches to messaging as well 
as informational approaches. Research is also needed into the dose (frequency and duration) of message delivery to achieve optimal audience or population reach and different outcomes, such as changes in awareness, knowledge, attitudes, motivation and behaviour.

In terms of influencing clinical practice, there is limited evidence on the best communication methods and channels to reach healthcare professionals. Future research is needed to understand how best to integrate physical activity into the curricula of relevant health-related academic and vocational courses to increase the knowledge and skillset of future healthcare workers. Research needs expand to acceptable and effective approaches to physical activity promotion in the healthcare sector. A future research focus on how to equip professionals in other sectors (eg teachers, transport engineers and town planners) with the knowledge and skills to integrate physical activity into their routine practice is also important.

\section{CONCLUSION}

The publication of global and national physical activity guidelines, among serving other functions, presents an opportunity to advance communication on physical activity and health to a range of audiences and to boost population physical activity. Effective communication to raise awareness and knowledge of the physical activity guidelines may not be enough; supportive policies, environments and opportunities for physical activity are essential components of a population behavioural change strategy. Besides the intrinsic value of the physical activity guidelines, it is essential that substantial effort is put in to diligently planning, funding and implementing their communication from the outset. Communication activities informed by formative research with the target audience and accompanied by a robust evaluation will build the evidence base on best practice in physical activity guidelines communication and beyond.

\section{What are the findings?}

- This paper presents a new planning framework to communicate global and national physical activity guidelines.

\section{How might it impact on clinical practice in the future?}

- Use of the planning framework may increase the effectiveness of communication and help maximise the impact of physical activity guidelines.

Twitter Karen Milton @karenmilton8,William Bellew @billbelleew, Chloë Williamson @Chlobobs_and Paul Kelly@narrowboat_paul

Contributors KM conceived the idea for the paper, in consultation with the coeditors of the special issue. KM and PK developed the initial scope of the article and prepared a first draft. AEB provided substantial input on the scope and structure of the paper. All authors contributed to refining the content of the manuscript and approved the final version.

Funding The authors have not declared a specific grant for this research from any funding agency in the public, commercial or not-for-profit sectors.

Competing interests $\mathrm{KM}$ and PK received financial reimbursement for some background work which informed parts of the manuscript. All other authors declare that they have no competing interests.

Patient and public involvement Patients and/or the public were not involved in the design, or conduct, or reporting, or dissemination plans of this research.

Patient consent for publication Not required.

Provenance and peer review Not commissioned; externally peer reviewed.
Data availability statement Data sharing not applicable as no datasets generated and/or analysed for this study.

Open access This is an open access article distributed in accordance with the Creative Commons Attribution Non Commercial (CC BY-NC 4.0) license, which permits others to distribute, remix, adapt, build upon this work non-commercially, and license their derivative works on different terms, provided the original work is properly cited, appropriate credit is given, any changes made indicated, and the use is non-commercial. See: http://creativecommons.org/licenses/by-nc/4.0/.

\section{ORCID iDs}

Karen Milton http://orcid.org/0000-0002-0506-2214

Chloë Williamson http://orcid.org/0000-0003-2148-7586

Paul Kelly http://orcid.org/0000-0003-1946-9848

\section{REFERENCES}

1 World Health Organization. Global recommendations on physical activity for health. Geneva: World Health Organization, 2010

2 Maziak W, Ward KD. From health as a rational choice to health as an affordable choice. Am J Public Health 2009;99:2134-9.

3 Kelly MP, Barker M. Why is changing health-related behaviour so difficult? Public Health 2016;136:109-16.

4 Scottish Government. The Scottish health survey 2013: volume 1: main report. Edinburgh: Scottish Government, 2014.

5 Dale LP, LeBlanc AG, Orr K, et al. Canadian physical activity guidelines for adults: are Canadians aware? App/ Physiol Nutr Metab 2016;41:1008-11.

6 Knox ECL, Esliger DW, Biddle SJH, et al. Lack of knowledge of physical activity guidelines: can physical activity promotion campaigns do better? BMJ Open 2013;3:e003633

7 Vaara JP, Vasankari T, Koski HJ, et al. Awareness and knowledge of physical activity recommendations in young adult men. Front Public Health 2019;7:310.

8 Kay MC, Carroll DD, Carlson SA, et al. Awareness and knowledge of the 2008 physical activity guidelines for Americans. J Phys Act Health 2014;11:693-8.

9 Hastings G. Social marketing: why should the devil have all the best tunes? Oxford: Elsevier Science \& Technology, 2007.

10 Glenton C, Lewin S, Lawrie TA, et al. Qualitative Evidence Synthesis (QES) for Guidelines: Paper 3 - Using qualitative evidence syntheses to develop implementation considerations and inform implementation processes. Health Res Policy Sys 2019;17.

11 World Health Organization. Stop the global epidemic of chronic disease: a practical guide to successful advocacy. Geneva: World Health Organization, 2006.

12 World Health Organization. Report of the inter-agency meeting on advocacy strategies for health and development: development communication in action. Geneva: World Health Organization, 1995

13 Leone L, Pesce C. From delivery to adoption of physical activity guidelines: realist synthesis. Int J Environ Res Public Health 2017;14:1193.

14 Latimer AE, Brawley LR, Bassett RL. A systematic review of three approaches for constructing physical activity messages: what messages work and what improvements are needed? Int J Behav Nutr Phys Act 2010;7:36.

15 Kingdon J. Agendas, alternatives and public policies. 2nd edn. New York: Harper Collins College Publishers, 1995.

16 Carlisle S. Health promotion, advocacy and health inequalities: a conceptual framework. Health Promot Int 2000;15:369-76.

17 Heath GW, Parra DC, Sarmiento OL, et al. Evidence-Based intervention in physical activity: lessons from around the world. Lancet 2012;380:272-81.

18 Bourne L. Targeted communication: the key to effective stakeholder engagement. Procedia Soc Behav Sci 2016;226:431-8.

19 Shilton T. Advocacy for physical activity - from evidence to influence. IUHPE Promotion \& Education 2006;XIII:118-26.

20 Chapman S. Public health advocacy and tobacco control: making smoking history. Chichester: John Wiley \& Sons, Inc, 2007.

21 Wipfli HL, Samet JM. Moving beyond global tobacco control to global disease control. Tob Control 2012;21:269-72.

22 Szarka J. From climate advocacy to public engagement: an exploration of the roles of environmental non-governmental organisations. Climate 2013;1:12-27.

23 Williamson C, Kelly P, Baker G, et al. A conceptual framework for physical activity messaging. Available: https://www.researchgate.net/publication/336956859_A_ conceptual_framework_for_physical_activity_messaging

24 Silva KS, Garcia LMT, Rabacow FM, et al. Physical activity as part of daily living: moving beyond quantitative recommendations. Prev Med 2017;96:160-2.

25 Williamson C, Baker G, Mutrie N, et al. Get the message? A scoping review of physical activity messaging. Int J Behav Nutr Phys Act 2020;17:1-5.

26 Evans DW, Hastings G. Public health Branding: applying marketing for social change. Oxford: Oxford University Press, 2008

27 Stead M, Angus K, Langley T, et al. Mass media to communicate public health messages in six health topic areas: a systematic review and other reviews of the evidence. Public Health Research 2018;7:ISSN2050-4381.

28 International Society for Physical Activity and Health. Investments that work for physical activity. 2nd edn. International Society for Physical Activity and Health, 2020 
29 Brown DR, Soares J, Epping JM, et al. Stand-Alone mass media campaigns to increase physical activity. Am J Prev Med 2012;43:551-61.

30 Wakefield MA, Loken B, Hornik RC. Use of mass media campaigns to change health behaviour. Lancet 2010;376:1261-71.

31 Kubacki K, Ronto R, Lahtinen V, et al. Social marketing interventions aiming to increase physical activity among adults. Health Educ 2017;117:69-89.

32 World Health Organization. Global action plan on physical activity 2018-2030: more active people for a healthier world. Geneva: World Health Organization, 2018.

33 Chatterjee R, Chapman T, Brannan MGT, et al. GPs' knowledge, use, and confidence in national physical activity and health guidelines and tools: a questionnaire-based survey of general practice in England. Br I Gen Pract 2017;OC tober:e688-e675.

34 Shuval $\mathrm{K}$, Leonard T, Drope J, et al. Physical activity counseling in primary care: insights from public health and behavioral economics. CA Cancer I Clin 2017;67:233-44.
35 Rose SA, Poynter PS, Anderson JW, et al. Physician weight loss advice and patient weight loss behavior change: a literature review and meta-analysis of survey data. Int J Obes 2013;37:118-28.

36 Reid H, Milton K, Bownes G, et al. Making physical activity evidence accessible - are these infographics the answer? Br J Sports Med 2016.

37 Dacey ML, Kennedy MA, Polak R, et al. Physical activity counseling in medical school education: a systematic review. Med Educ Online 2014;19:24325.

38 Milton K, Larner J, Hanson S, et al. Embedding Physical Activity into the Healthcare Curriculum - A Case Study. Educ Prim Care 2020;31:176-9.

39 Brannan M, Bernardotto M, Clarke N, et al. Moving healthcare professionals - a whole system approach to embed physical activity in clinical practice. BMC Med Educ 2019;19:84.

40 Bull F, Milton K. Let's Get Moving: a systematic pathway for the promotion of physical activity in a primary care setting. Glob Health Promot 2011;18:59-61.

41 Russell E. Exercise is medicine. CMAJ 2013;185:E526. 